\title{
The effect of sugammadex on the vascular tone of isolated rat aorta
}

\author{
Soo Hee Lee ${ }^{1,2}$, Ji-Yoon $\mathrm{Kim}^{3}$, Sunmin $\mathrm{Kim}^{3}$, and Ju-Tae Sohn ${ }^{1,2}$ \\ ${ }^{1}$ Department of Anesthesiology and Pain Medicine, Gyeongsang National University Hospital, Gyeongsang National \\ University School of Medicine, ${ }^{2}$ Institute of Health Sciences, Gyeongsang National University, ${ }^{3}$ Department of \\ Anesthesiology and Pain Medicine, Gyeongsang National University Hospital, Jinju, Korea
}

The $\gamma$-cyclodextrin, sugammadex, produces a rapid reversal of the neuromuscular blockade induced by the nondepolarizing agents rocuronium and vecuronium via encapsulation, leading to rapid recovery from muscle relaxants used in surgery. It has been reported that intravenous administration of sugammadex rarely causes hypotension induced by anaphylaxis and hypersensitivity reactions [1,2]. As histamine, released from mast cells and basophils activated by anaphylaxis or type I hypersensitivity reactions causes vasodilation, which seems to contribute to sugammadex-induced hypotension observed in previous reports via the indirect mechanism [3]. Conversely, sugammadex may produce coronary vasospasm in variant angina, which leads to cardiac arrest [4]. However, the direct effect of sugammadex on vasoreactivity (vascular tone) remains unknown. Thus, we investigated the direct effect of sugammadex on the contraction induced by the contractile agonist, norepinephrine released from sympathetic nerve endings, and by the voltage-operated calcium channel activator, $\mathrm{KCl}$, using isometric tension measurements of isolated rat aorta, as described previously [5]. We obtained approval for this experimental protocol from the Animal Care and Use Committee of Gyeongsang National University. After 60 $\mathrm{mM} \mathrm{KCl}$ or norepinephrine $\left(10^{-6} \mathrm{M}\right)$ produced a sustained and stable contraction in isolated endothelium-intact and endothelium-denuded rat aortas, sugammadex $\left(10^{-6}\right.$ to $\left.3 \times 10^{-4} \mathrm{M}\right)$ was

Corresponding author: Ju-Tae Sohn, M.D.

Department of Anesthesiology and Pain Medicine, Gyeongsang National University Hospital, 79, Gangnam-ro, Jinju 52727, Korea

Tel: 82-55-750-8586, Fax: 82-55-750-8142

Email: jtsohn@gnu.ac.kr

ORCID: https://orcid.org/0000-0003-0102-5800

Received: October 7, 2017.

Revised: January 25, 2018.

Accepted: January 29, 2018.

Korean J Anesthesiol 2018 June 71(3): 242-243

https://doi.org/10.4097/kja.d.17.00035 cumulatively added to the organ bath to produce sugammadex dose-response curves. Sugammadex $\left(10^{-6}\right.$ to $\left.3 \times 10^{-4} \mathrm{M}\right)$ had no effect on the contraction induced by norepinephrine $\left(10^{-6} \mathrm{M}\right.$, Fig. 1A and 1B) or $60 \mathrm{mM} \mathrm{KCl} \mathrm{(Fig.} \mathrm{1C} \mathrm{and} \mathrm{1D)} \mathrm{in} \mathrm{the} \mathrm{isolated}$ endothelium-intact and -denuded rat aortas. The results suggest that sugammadex itself, in a dose that exceeds the clinical dose of sugammadex $\left(10^{-5} \mathrm{M}\right)$, has no direct effect on voltageor receptor-operated calcium channels or endothelium-derived vasodilators, including nitric oxide, which contribute to vascular tone modulation. However, the present study has the following limitations. First, as protein kinase $\mathrm{C}$ and Rho-kinase in vascular smooth muscle are involved in vasoconstriction mediated by calcium sensitization, further study regarding the effect of sugammadex on the contraction induced by the protein kinase C stimulant phorbol 12,13-dibutyrate or the Rho-kinase stimulant $\mathrm{NaF}$ is needed. Second, small resistance arterioles such as the mesenteric artery rather than the aorta as a conduit vessel are mainly involved in the regulation of peripheral vascular resistance. In spite of these limitations, the results of the present study, when taken together, suggest that sugammadex has no direct effect on the vascular tone of isolated vessels.

\section{Funding Statement}

This research was supported by Basic Science Research Program through the National Research Foundation of Korea (NRF) funded by the Ministry of Education (NRF-2016R1D1A1B03930451).

\section{ORCID}

Soo Hee Lee, https://orcid.org/0000-0002-6047-633X Ji-Yoon Kim, https://orcid.org/0000-0001-7998-8936 Sunmin Kim, https://orcid.org/0000-0002-1950-4423 Ju-Tae Sohn, https://orcid.org/0000-0003-0102-5800

(c) This is an open-access article distributed under the terms of the Creative Commons Attribution Non-Commercial License (http://creativecommons.org/ licenses/by-nc/4.0/), which permits unrestricted non-commercial use, distribution, and reproduction in any medium, provided the original work is properly cited. 
A
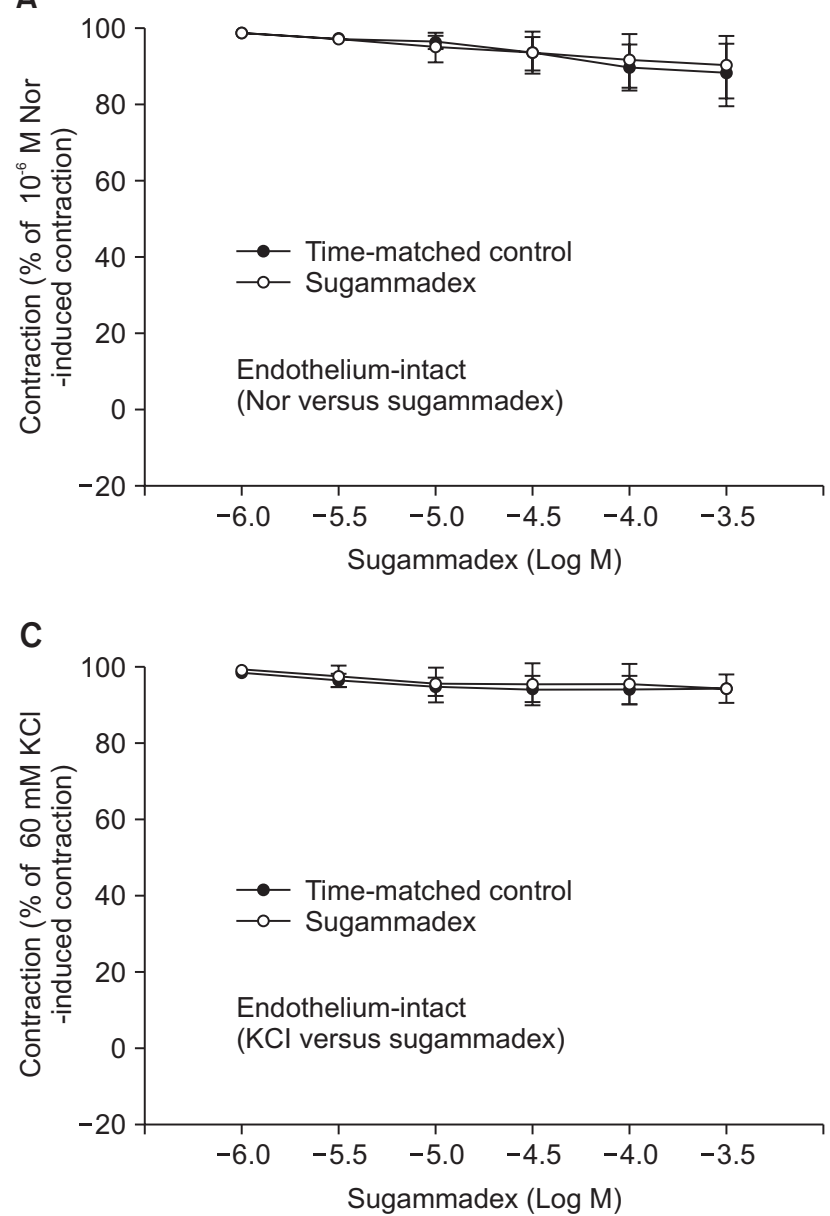

B
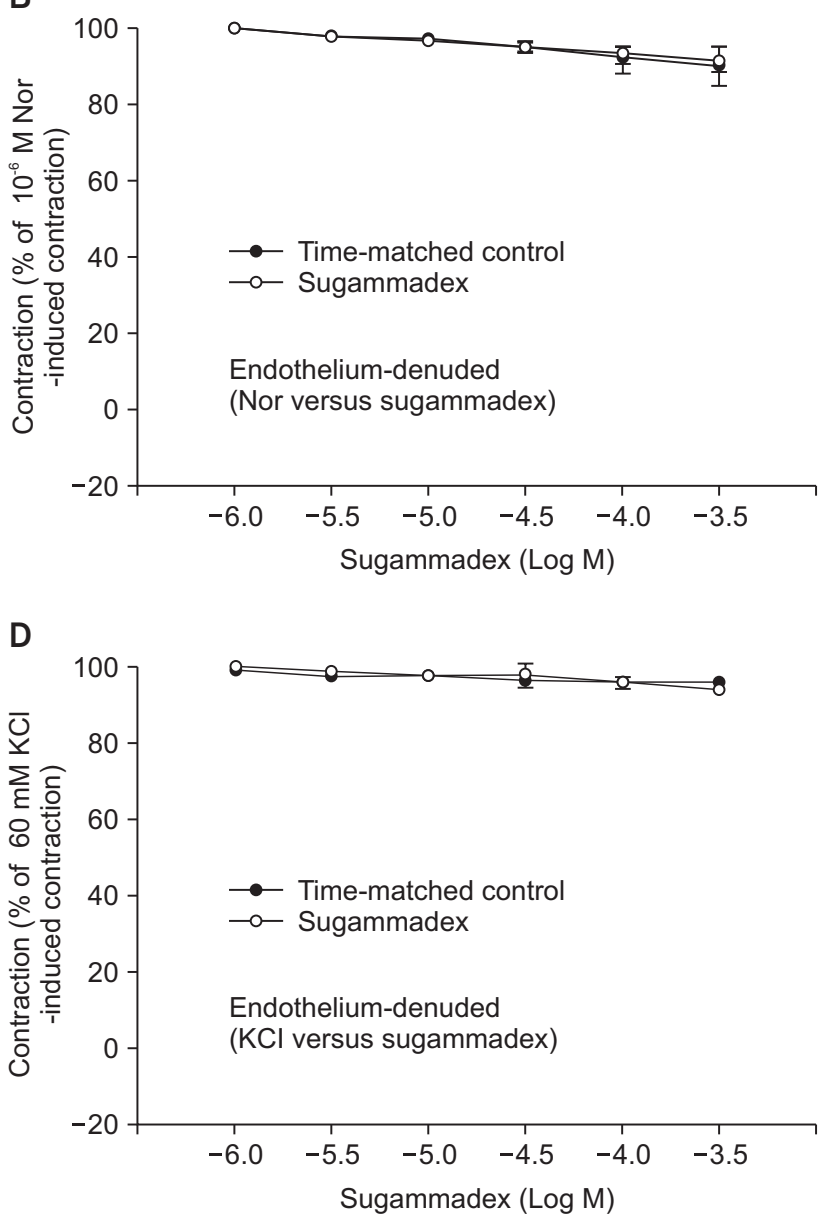

Fig. 1. Effect of sugammadex on the contractions induced by norepinephrine (Nor) or $\mathrm{KCl}$ in isolated endothelium-intact rat aortas (Nor: $\mathrm{N}=7 ; \mathrm{KCl}$ : $\mathrm{N}=8$ ) and -denuded (Nor: $\mathrm{N}=7 ; \mathrm{KCl}: \mathrm{N}=6$ ). Data are shown as mean \pm standard deviation $(\mathrm{SD})$ and are expressed as the percentage of contraction induced by norepinephrine or $\mathrm{KCl}$. $\mathrm{N}$ indicates the number of isolated rat aortic rings.

\section{References}

1. Godai K, Hasegawa-Moriyama M, Kuniyoshi T, Kakoi T, Ikoma K, Isowaki S, et al. Three cases of suspected sugammadex-induced hypersensitivity reactions. Br J Anaesth 2012; 109: 216-8.

2. Yoo JH, Kim SI, Ok SY, Park SY, Cho A, Han YM, et al. Suspected anaphylactic reaction associated with sugammadex: a case report. Korean J Anesthesiol 2016; 69: 413-6.

3. Peavy RD, Metcalfe DD. Understanding the mechanisms of anaphylaxis. Curr Opin Allergy Clin Immunol 2008; 8: 310-5.

4. Ko MJ, Kim YH, Kang E, Lee BC, Lee S, Jung JW. Cardiac arrest after sugammadex administration in a patient with variant angina: a case report. Korean J Anesthesiol 2016; 69: 514-7.

5. Ok SH, Kim WH, Yu J, Lee Y, Choi MJ, Lim DH, et al. Effects of acidification and alkalinization on the lipid emulsion-mediated reversal of toxic dose levobupivacaine-induced vasodilation in the isolated rat aorta. Int J Med Sci 2016; 13: 68-76. 